\title{
Implementation of Total Quality Management at Aircraft Maintenance Department
}

\author{
Waqar Hussain ${ }^{1}$, Jabeen Zahra ${ }^{2}$, Sohail Anwar ${ }^{3}$, Dr Syed Abdul Aziz ${ }^{4}$ \\ ${ }^{I}$ Research Scholar, HIESS, Hamdard University, Karachi, Pakistan \\ 2 IT Instructor Tahir Science Academy, Lahore, Pakistan \\ ${ }^{3}$ Assisstant professor, Department of pharmacy, Hamdard University, Karachi, Pakistan \\ ${ }^{4}$ Research Supervisor, HIESS, Hamdard University, Karachi, Pakistan
}

\begin{abstract}
This study will explain how Total Quality Management can be implemented at the second line aircraft maintenance department of Pakistan Naval Aviation. The TQM Implementation process can be established by considering four important elements: Top management commitment, present indoor quality culture of the second line maintenance activities, ISO certification of the organization, and the built in TQM characteristics of Pakistan Naval Aviation. The instructions and guide lines of Naval Aviation Maintenance Manual UK and Group Officer Quality Assurance at Air Engineering Department along with the intellectual support of Sir Imranullah Shriff will be used for TQM implementation. Aircraft Maintenance Control Office, Group Officer Quality Assurance and Group Officer Air Engineering Training are the help lines to be approached for assistance for TQM implementation. Battery shop is presented as TQM model work shop for other shops of second line maintenance activities for using it as a bench mark. The project recommends the methodologies for the implementation process of TQM. An understanding of the hurdles to the TQM implementation process, for corrective actions improvements, suggestions and recommendations will shape the end of the project.
\end{abstract}

Key Words: Aircraft Maintenance Control Office (AMCO), continuous improvement, Indoor quality culture, second line maintenance activities (SLMA), Total quality management (TQM)

\section{Introduction}

To keep touch with up to date technologies in Aviation Industries and to guarantee the quality standards for its flight/ ground safety, it is felt with great concern that there is a need of TQM to its engineers, associate engineers and technicians to enhance the operation, servicing and engineering/technical skills of staff of second line maintenance department at Pakistan Naval Aviation. (COMNAV order: 14). Implementation of TQM at the second line aircraft maintenance department is the prime objective of this project. Research questions are 1- Is it possible to implement TQM at second line aircraft maintenance activities? 2. How TQM implementation process can be assisted? 3. What are the hurdles to the implementation process? This research is only limited for second line aircraft Maintenance Activities. It is assumed that the reader is already familiar with aircraft maintenance activities and management culture of second line aircraft maintenance activities because the research's present motive is to facilitate second line aircraft maintenance activities only.

\section{Methodology and Litrature Review}

The project begins by getting permission from Commander Naval Aviation. This is also a representation of top management commitment. It then identifies the TQM help lines available to assist TQM implementation. This research follows the PDCA (PLAN-DO-CHECK-ACT) cycle of Shewart. While qualitative and semi quantitative approach is used for this study. Questionnaire and interview are the sources of data collection. Review of litrature is be done by resources available as 1-TQM lectures of sir Imranullah Sheriff ,Quality guide of Dr Kamran Mussa,listing of previous work done in the field of Total Quality Management in aviation industry, Aviations Maintenance Manuals, Procedure Manuals, SOPS, TQM research journals, Quality Manual and Navy Rule. Quality is defined in different ways by various authors. Crosby (1979) defined quality as the "conformance to requirements or specifications" ([1]). ISO 9000: 2000 defined quality as "the degree to which a set of inherent characteristics fulfill requirements". ([2]. "Quality is safety" ([3]). Quality management includes the functions like planning, organizing, staffing. Directing and controlling for the management of TQM in the organization. ([4]) "Inspection is activity to measure that whether a product or service conforming a standard or not. It may be done in the form of measurement, examination and testing". ([5]). Quality control may generally be defined as "a system that is used to maintain a desired level of quality in a product or service ([6])"Quality controls are operational techniques and activities that are used to fulfill quality requirement" ([7]). Quality assurances are the preventive measures particularly in design phase of a product 
"process or service which gives confidence that required standard of quality will be achieved". ([8]) TQM is the highest level of quality. TQM is the integration of all functions and process within an organization in order to achieve continuous improvement of the quality of goods and services. The goal is customer satisfaction. ([9]). the aircraft maintenance is divided into three categories: organizational level or first line, second line or shop level, and third line or depot level. The first line maintenance is done by the flight line personnel at squadron premises this includes removal and installation of components and flight servicing. The shop level is responsible for the repair of the aircraft components removed at the flight line. While the third line deals the overhauling of aircrafts components. The typical executive element is an aircraft squadron. The shop level organizations are known as Aircraft Second Line Maintenance Departments (ASLMD) or Second Line Maintenance Activities (SLMA). The depot level activities are called Major overhaul section (MOHS). ([10])

\section{Implementation of TQM}

To successfully manage change, all organizations must have the support of top management. Commander Naval aviation issued orders for full support and provision of the resources for this project. "I encouraged all aviators within second line aircraft maintenance activities to provide support and cooperation to the project team and should play their part for continuous improvement in maintenance practices" ([11)].The indoor operational cycle that second line maintenance activities operate in gives itself support to the implementation of Total Quality Management. A logistic support organization is known as the PNS RAZA act as Aviation Supply Department (ASD) for aircraft spares. When a flight line removes a defective component, that component is send to PNS RAZA for a replacement. The defective component passes from supply to the second line maintenance activity for repair. The SLMA and supply form a closed cycle with each one's output, the other's input. One of the basic requirements of Total Quality Management is continuous process improvement. Thus, the SLMA and supply relationship lends itself to such measures of effectiveness. Repair turn-around times, awaiting parts time, awaiting maintenance time, cause of failure, and most-frequently repaired- parts are just a few of the measurements already recorded by the existing data control system. Air engineering department is an ISO 9001-2000 certified organization which gives strong bases for TQM implementation. As a result of the job rotation of ISO trained uniform personnel by every three years, it maintain the pool of trained personnel who are already aware of knowledge of TQM .TQM promote the use of paramount management tools, a few of them are already experienced within the second line aircraft maintenance activities . One such plan is the best aviator of the month and best sailor of the year. Its objective is to: "encourage aviators to suggest in realistic ways to reduce defects and improve efficiency while maintaining the flying assets". ([12]) it also provides a formal direction for communications between management and technicians for maintenance issues. The model open forums for suggestion and on the site solution for quality issues are another plan which helps in the teachings of TQM. Still another feature of TQM that already available is the use of statistical process control. ([13]) it states that the purpose of the trend analysis plan is enabling air engineering officers to establish the frequency and types of defects being produced. So that timely corrective action can be indicated. These all factors give strong support for implementation of TQM.

\section{The TQM Helps Lines}

There are three TQM help lines that second line aircraft maintenance activities can go round to for help. They are the Group Officer Air Engineering Training (GO AET), Aircraft Maintenance Control Office (AMCO), and GO QA, The Aviation Quality Group. GO AET set up the Quality Enhancement Cell (QEC) for TQM teaching and Training. The purpose of this (QEC) was to prepare a plan for TQM education and training all over the second line aircraft Maintenance Activities. This deliberated plan has two main goals: 1-Introduction of TQM."2- Training of staff for TQM implementation. The prime goal of QEC was the preparation of a general TQM training Course. GO QA is the sole group which is responsible for overall quality of maintenance as well as the training of the quality inspectors' .it holds management review meetings and other training seminars on a planned interval throughout the year. SLMA has also taken the lectures and written material for TQM implementation from QA . They are well trained staff equipped with digital library and international qualified instructors. Hence QA can be used as the best resource centre and help line for TQM implementation. The Aircraft Maintenance Control Office is established in accordance with Naval Aviation Maintenance Manual (UK) to serve as the hub for Air engineering department maintenance performance improvement matters. AMCO's association with TQM therefore came as a likely development of the efficiency enhancement plan. It is also responsible for timely maintenance of aircraft, it forecast the aircraft serviceability for both schedule and unscheduled maintenance, it is a custodian of all the maintenance and repair data of aircraft also conduct the training of engineers and technicians. AMCO provided TQM training to second line aircraft maintenance activities (SLMA) staff through a workshop. Aircraft Maintenance Control Office has become the TQM help line for second line aircraft maintenance activities for TQM implementation. AMCO supported in the 
development of the TQM awareness module that is being taught to all trainee engineers and technician which is edit by the course material of TQM taught at PIQC for their MS program.

\subsection{GO QA IMPROVEMENT}

\section{The TQM Models \& Workshop}

The GO QA holds a TQM Implementation training workshop which presented an improvement model ([14]). The intention of this training is to educate SLMA staff on how to develop the relationship with AMCO coordinator for TQM implementation this workshop has 04 sessions: TQM designing, Planning, implementation, and continuous improvement.

\subsubsection{TQM DESIGNING}

The workshop starts with an evaluation of the fundamental TQM ideas and philosophies. Total quality management is defined at the seminar as: TQM is the application of levels of quality and people to judge and improve. These levels are inspection, quality control, quality assurance, continuous quality improvement, and attempted approach to PMQA Pakistan. The TQM design is drawn from the Dr Kamran Mussa's quality guide (Urdu version) [(15])

\subsubsection{PLANNING}

TQM planning includes the change management in following aspects: TQM as a successful tool of improvement, TQM targets, the TQM team, and TQM change management plan. The significance of this component of the workshop is that to successfully implement TQM within the SLMA, an innovative attitude must be adopted. TQM targets must be settled in the form of vision and how these targets will be achieved. The vision and objective of the project was briefed to all SLMA staff. The TQM team must be ready to initiate corrective actions. TQM change management plan interlink the TQM targets, continuous improvement at SLMA and the TQM team. The change is announced so that ideas, suggestions and hurdles to TQM implementation can be assessed.

\subsubsection{IMPLEMENTATION}

This part of the seminar include the introduction of ,Commander Air Engineering and SLMA staff as process owners and process workers are the TQM team members. TQM implementation is carried by adopting the philosophies of TQM like. Give direction as to what to do, commitment to targets, and Customer satisfaction. GO AET explains need and quantity of training required by SLMA staff. A small segment of the workshop is dedicated to an internal audit and assessment training for evaluation of TQM implementation. Finally plan for TQM Implementation was given which include list of individual goals that must be achieved in the implementation.

\subsubsection{CONTINUOUS IMPROVEMENT}

PDCA model is the subject of the final phase. It is based on Shewhart's Plan-Do-Check-Act Cycle which is linked with the TQM implementation structure. A short outline of statistical process control concludes this training work shop.

\subsection{AMCO'S WORKSHOP}

AMCO provides a TQM approach model in three lectures, which includes: planning, training, inspection, process improvement, and process audits. ([16])

\section{2 .1 AMCO lecture 1}

This part consists wholly of the planning phase, which composed of a top management commitment, role of TQM team, Training and lesion learnt. Top management commitment for Implementation of TQM is delivered in the form of written message of Commander Naval Aviation. Process ownership, voice of customer, team formation, and participative attitude is presented in the start of the lecture. The role and composition of the TQM team, quality enhancement cell, are explained to SLMA staff. Plan-Do-Check-Act Cycle is used to introduce the Continuous Process Improvement model applied in Pakistan Air Force at PAF Faisal shop level maintenance department ([17]). Remaining parts were inspection, improvement, and audits phases.

\subsubsection{AMCO lecture 2}

It include education phase, followed by the inspection and process improvement training. SLMA staff was given knowledge about the graphical tools of TQM. 7 QC tools, benchmarking, house of quality, co relation and basic statistics. The SLMA staff was interviewed and assed by a 15 mints written paper for assessment. This was checked and discussed at the spot to remove the implementation hurdles and confusions. The results of 
audits and results of paper give the direction for improvement. The staff required special help are redirected and were given additional support.

\subsubsection{AMCO lecture 3}

This lecture includes Evaluation Phase. The intention is to measures the effectiveness. If the measures do not show change, the actual planning is Re-evaluated and the process improved by corrective action. The TQM team will do surveillance audit in such case.

\section{Data Analysis and Findings}

A staff of 125 technicians is working in SLMA in which 100 are uniform personnel and 25 are civilians. so the questionnaire is distributed to a sample size of 30 which is $25 \%$ of the population. A total of 30 questionnaires were distributed and all are responded. The questionnaires consist of three portions, which aim on the areas of interest of the research. Part-1(Awareness of TQM ideology), Part-2(Support factors for TQM implementation) and Part-3(Hurdles for TQM implementation.).The tables show the results of the data. The keys for tables $\mathrm{U}$ (uniform technician), C (civilian), \% (percentage), $\mathrm{S} / \mathrm{L}$ (scale level) and $\mathrm{T}$ (Total).The data below show give information that $83 \%$ of the staff having knowledge of TQM.92.3\% of the population believe that the top management commitment, ISO certification of the organization ,built in TQM characteristics and present indoor quality culture of second line maintenance activities are the support factors for TQM implementation while $86.6 \%$ of the population agree that Confidentiality of the organization, Law and order situation in the city, non availability of TQM team members, existence of the multi management and maintenance systems, Operational urgency and work load are the hurdles to TQM implementation.

Table-1(Awareness of TQM ideology)

\begin{tabular}{|l|l|l|l|l|}
\hline Part -1 & U & C & T & $\%$ \\
\hline $\begin{array}{l}\text { NO } \\
\text { KNOWLEDGE }\end{array}$ & 2 & 3 & 5 & $\mathbf{1 6 . 6 6 \%}$ \\
\hline $\begin{array}{l}\text { HAVE } \\
\text { KNOWLEDGE }\end{array}$ & 23 & 2 & 25 & $\mathbf{8 3 . 3 3 \%}$ \\
\hline TOTAL & 25 & 5 & 30 & $100 \%$ \\
\hline
\end{tabular}

Table-2(Support factors for TQM implementation)

\begin{tabular}{|l|l|l|l|l|l|}
\hline Part-2 & $\begin{array}{l}\text { S/ } \\
\text { L }\end{array}$ & U & C & T & $\%$ \\
\hline Strongly agree & 5 & $\mathbf{1 8}$ & $\mathbf{0 2}$ & $\mathbf{2 0}$ & $\mathbf{6 6 . 6 6 \%}$ \\
\hline Agree & $\mathbf{4}$ & $\mathbf{0 5}$ & $\mathbf{0 3}$ & $\mathbf{0 8}$ & $\mathbf{2 6 . 6 6 \%}$ \\
\hline Neutral & $\mathbf{3}$ & $\mathbf{0 2}$ & nil & $\mathbf{0 2}$ & $\mathbf{6 . 6 6 \%}$ \\
\hline Not agree & $\mathbf{2}$ & Nil & nil & nil & Nil \\
\hline Strongly not agree & $\mathbf{1}$ & Nil & nil & nil & Nil \\
\hline Total & & $\mathbf{2 5}$ & $\mathbf{0 5}$ & $\mathbf{3 0}$ & $\mathbf{1 0 0 \%}$ \\
\hline
\end{tabular}

Table-3(Hurdles for TQM implementation.

\begin{tabular}{|l|l|l|l|l|l|}
\hline Part-3 & $\mathrm{S} / \mathrm{L}$ & $\mathrm{U}$ & $\mathrm{C}$ & $\mathrm{T}$ & $\%$ \\
\hline Strongly agree & $\mathbf{5}$ & $\mathbf{1 5}$ & $\mathbf{0}$ & $\mathbf{1 5}$ & $\mathbf{5 0 \%}$ \\
\hline Agree & $\mathbf{4}$ & $\mathbf{0 8}$ & $\mathbf{0 3}$ & $\mathbf{1 1}$ & $\mathbf{3 6 . 6 6 \%}$ \\
\hline Neutral & $\mathbf{3}$ & $\mathbf{0}$ & $\mathbf{0 1}$ & $\mathbf{0 1}$ & $\mathbf{3 . 3 3 \%}$ \\
\hline Not agree & $\mathbf{2}$ & $\mathbf{0 2}$ & $\mathbf{0 1}$ & $\mathbf{0 3}$ & $\mathbf{1 0 \%}$ \\
\hline Strongly not agree & $\mathbf{1}$ & $\mathbf{0}$ & $\mathbf{0}$ & $\mathbf{0}$ & $\mathbf{0}$ \\
\hline Total & & $\mathbf{2 5}$ & $\mathbf{0 5}$ & $\mathbf{3 0}$ & $\mathbf{1 0 0 \%}$ \\
\hline
\end{tabular}

VII. Suggestion and Recommendations

Second line maintenance activities wishing to implement Total Quality Management should utilize the TQM help lines. It should consider both GO QA seminar and AMCO's lectures for implementation process.

Quality assurance group is the best in house source of TQM implementation with diversity of experience and knowledge of international quality management system like ISO. So it must be utilized for effective TQM implementation. Aircraft Maintenance Control Office has held the workshop to educate the SLMA staff for TQM implementation. So these productive contents of the work shop must be brought into consideration for structured approach to TQM implementation. SLMA should target and train the main staff early in the 
implementation process. These key personnel are the Group Officer SLMA, Deputy Group Officer SLMA (AVN).DGO (l), DGO (R/R) and all the concern group chief petty officers. Chief store, chief quality, trade chiefs, supply coordinator TQM team and the data analyst are also included. The TQM Coordinator will act as a change agent within the organization. A change agent possesses certain values which are: uprightness and determination, realistic awareness of the organization's processes and outputs, Good and impressive interpersonal skills, effective communication skills, enthusiasm and inventiveness, Inventive ability and imagination and best Knowledge of total quality management The battery shop should be used as a model work shop for this project as it is easily approached and having diversity of technicians. This model shop will serve as bench mark for other shops of SLMA. It is done so that implementation of TQM starts in segments of big picture and for easy handling of the project and effectiveness. This TQM structure is selected so that all the stakeholders of SLMA are benefited from this project regarding the TQM structure's organizational effectiveness, it can also help identify future training requirements. These inputs will provide valuable guidance when developing an in-house training capability. The TQM beliefs should be implemented descending order of management.

\section{Conclusion}

Total Quality Management in second line maintenance activities department of Pakistan Naval Aviation can be implemented.

\subsection{ANSWER TO PRIMARY RESEARCH QUESTION AND RECOMMENDATIONS}

Can Total Quality Management be implemented at second line maintenance activities? Yes. There are four major factors supporting this answer. First, the implementation of TQM is supported by the top leadership (Commander Naval Aviation). Secondly, the indoor second line maintenance culture helps the implementation of TQM by virtue of its built in available procedures of efficiency. Thirdly, the organization is already ISO certified provided strong bases for TQM implementation and finally, several components of the TQM values like reward system, employee involvement, focusing on continuous improvement, communication excellence, use of SPC and benchmarking already exist within the second line aircraft maintenance activities.

\subsection{SECONDARY QUESTIONS AND RECOMMENDATIONS}

How TQM implementation at SLMA can be assisted? SLMA can receive help primarily from the AMCO, GO QA and GO AET and use of model work shop as bench mark for other shops. What are some of the hurdles to the implementation process? One of the major hurdle to the implementation process at the SLMA are the use of old methods and more paper work for the maintenance requisitions .SLMA must utilized its new data management system (Naval Aviation Maintenance Management System. Another obstacle to overcome is the rotation of technical personnel after every three year this period can be increased to five years for effective use of trained personnel at SLMA. Finally, the SLMA must institute an in house capability of incorporated training for the TQM structure in the form of self supervision and credentials.

\subsubsection{FURTHER REQUIREMENT OF STUDY}

The further study on the implementation of TQM at whole organization level is required secondly the role of TQM help lines needs further exploration for affectivity and continuous improvement.

\section{References}

[1] Amitava Mitra (2 ${ }^{\text {nd }}$ Edition 2002) "Fundamentals of Quality Control and Improvement" (2 ${ }^{\text {nd }}$ Edition 2002)1-24 international print edition

[2] "Practical Guide to ISO 9001:2000 Quality Management System.”(3 ${ }^{\text {rd }}$ Edition 2007) by Kamran Moosa \& Imranullah Shariff

[3] Naval Aviation Maintenance Manual (UK) Chapter 35

[4] Amitava Mitra (2 $2^{\text {nd }}$ Edition 2002) "Fundamentals of Quality Control and Improvement" (2 ${ }^{\text {nd }}$ Edition 2002)1-23 international print edition.

[5] Dr Kamran Moosa, ICQI 2011, Pakistan TQM implementation and its dynamics" printed in PIQC

[6] Dale H. Bester field, (3 ${ }^{\mathrm{RD}}$ Edition)" Total Quality Management" international print edition

[7] Kamran Moosa, 2000," Quality Management Practices".2-15

[8] Lectures of Sir Imranullah Shariff delivered at PIQC Karachi.(march2012-july 2012)

[9] Robert J. Master, “Overcoming the Barrier of TQM's Success". Quality Progress (May 1996):53-55

[10] Naval Aviation Maintenance Manual (UK) Chapter 36

[11] (COMNAV orders 2012) at PNS MEHRAN Pakistan

[12] Navy rule UK (Award instructions-ch-1) 1990.

[13] Naval Aviation Maintenance Manual (UK) Chapter 34

[14] (Group officer Training Schedule-TS /SEP.15/13) at PNS MEHRAN Pakistan

[15] Quality Guide of Dr Kamran Moosa. Urdu version

[16] (Group officer Training schedule TS/SEP 20/13) at PNS MEHRAN Pakistan.

[17] PAF quality instruction 2005, practiced at Faisal Base Karachi Pakistan. 